\title{
Guidelines or gospels?
}

\author{
Thoralf M. Sundt, MD
}

\begin{abstract}
In the interest of advancing evidenced-based medicine, enthusiasm for clinical practice guidelines has skyrocketed. They have a genuine impact on clinical practice and are frequently referenced in the literature. Their construction is complex and labor intensive, and has significant limitations given the necessary process as well as the data available. There has been less focus on their appropriate clinical application as dictated by these inherent limitations. It is worthwhile taking a step back and considering how we know what we think we know based on statistical analysis of biomedical data sets and the real implications of those population data for making predictions about the individual patient we encounter in the clinic. These data as used to establish guidelines for care should be the foundation and starting point for our thoughtful recommendations and decision making, not the final word. The importance of nuance in clinical judgment remains even in this “evidence-based" world. (J Thorac Cardiovasc Surg 2016;151:1472-4)
\end{abstract}

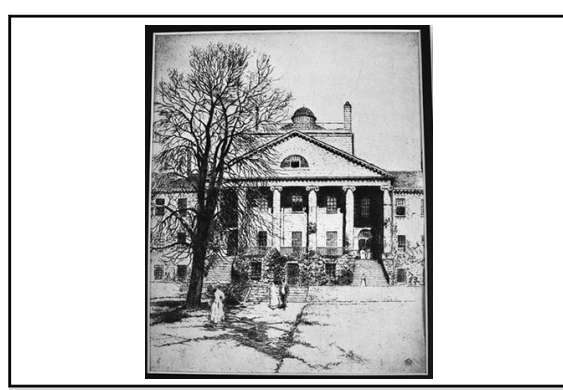

Guidelines must be applied in a patient-centered, individualized manner in the clinic.

\section{Central Message}

There is an increasing focus on creation of clinical guidelines, but much less attention on their appropriate use and limitations when applied to individual patients.

\section{Perspective \\ The biomedical research upon which guide- lines are built depends on mathematical methods of statistical analysis. This approach to probability is so familiar that we may not consider the limitations it places on our ability to estimate the likelihood of alternate outcomes for individual patients. Treatment recommen- dations should be nuanced by an appreciation of the assumptions inherent in our methods.}

See Editorial Commentary page 1474.
"If you follow the guidelines perfectly, to the letter, without fail ... you are not doing your job."

$$
\text { -Blase Carabello }
$$

I have found myself thinking a lot about guidelines of late, both how they are made and, much more to the point, how they are used. I was recently privileged to participate in the construction of the American College of Cardiology (ACC)/American Heart Association (AHA) guidelines for the treatment of valvular heart disease, which was itself a terrific educational experience. But even more so, I found

From the Division of Cardiac Surgery, Massachusetts General Hospital, Harvard Medical School, Boston, Mass.

Received for publication Jan 30, 2016; accepted for publication Feb 7, 2016; available ahead of print March 16, 2016.

Address for reprints: Thoralf M. Sundt, MD, Division of Cardiac Surgery, Massachusetts General Hospital, Harvard Medical School, 55 Fruit St, Boston, MA 02114 (E-mail: tsundt@mgh.harvard.edu).

$0022-5223 / \$ 36.00$

Copyright (C) 2016 by The American Association for Thoracic Surgery http://dx.doi.org/10.1016/j.jtcvs.2016.02.017 myself in the midst of a controversy over indications for replacement of the ascending aorta in the setting of a bicuspid aortic valve, from which I think I have learned even more about the challenges that guidelines present for the practicing clinician. Still, it seems that the more I learn, the less I know.

Clinical practice guidelines are created with all the best intentions as a tool to facilitate decision making. They are a reflection of our earnest desired to practice evidencebased medicine, reduce needless variation, and improve outcomes for our patients. Clinicians are increasingly pressured for time, and data are accumulating at an exponential rate. Few if any clinicians in any field can truly claim to be an expert in all aspects of their practice, making the market demand for guidelines hot. Accordingly, it seems that we are literally awash in them. The National Guidelines Clearing House, an initiative of the Agency for Healthcare Research and Quality, contains more than 2000 individual guideline summaries (http://www.guideline.gov/browse/ index.aspx?alpha $=\mathrm{A}$ ), and even within our own specialty, 
the proliferation is readily apparent in both our published literature and educational programs.

Much has been written about the proper synthesis of guidelines by those with a much deeper understanding of the topic than I. At the request of the US Congress, in 2011 the Institute of Medicine released a report titled "Clinical Practice Guidelines We Can Trust" (http://iom. nationalacademies.org/reports/2011/clinical-practice-guide lines-we-can-trust.aspx) establishing the standards for guideline development. The ACC and AHA have a longstanding and careful process for guideline development, and more recently both the Society of Thoracic Surgeons and The American Association for Thoracic Surgery have established working groups and standards. Hopefully, the analogy to making sausages ("while you like the product, you really do not want to know how it is made") no longer holds. But what about their consumption?

The proliferation of guidelines inescapably creates challenges for the clinician trying to use them. With numerous organizations of multinational origin and multidisciplinary composition writing about complex topics each from its own perspective, both inconsistencies in specific recommendations and glaring gaps are inevitable. As evidence accumulates, knowledge evolves and recommendations will appropriately change. I experienced this first hand when the 2014 ACC/AHA guideline for the management of patients with valvular heart disease ${ }^{1}$ recommendations for the threshold for intervention for a dilated ascending aorta in the presence of a bicuspid aortic valve differed from those published only 4 years earlier in the American College of Cardiology Foundation/AHA Task Force on Practice Guidelines, American Association for Thoracic Surgery, American College of Radiology, American Stroke Association, Society of Cardiovascular Anesthesiologists, Society for Cardiovascular Angiography and Interventions, Society of Interventional Radiology, Society of Thoracic Surgeons, and Society for Vascular Medicine guidelines for the diagnosis and management of patents with thoracic aortic disease. ${ }^{2}$ The differences have been clarified in a recent publication, ${ }^{3}$ but I was naively unprepared for the degree to which the shift was unsettling to clinicians, both surgical and medical. Clinicians would ask me, "So what am I supposed to do now? The guidelines said this, and now they say something else." I have come to interpret this, again with $\mathrm{Dr}$ Carabello's wisdom, as a challenge, not so much in how guidelines are made, as in how they are interpreted and used.

Guidelines are not gospels. The recommendations themselves are nuanced in their strength-class I, class IIa, and class IIb-ranging from "should" or "is recommended" to "may/might be considered." Much more than this, however, the evidence on which they are established has limitations. We express these limitations in part as A, B, or C, reflecting the number of studies and the rigor with which they were performed. Of course, there are many now- familiar arguments about the positive and negative attributes of both randomized studies - elimination of treatment bias and presumed neutralization of unmeasured covariates at the cost of representativeness of the population as a whole-and retrospective or registry studies for which the converse is the case. But there is a more subtle aspect of these data that has direct implications for their applicability in the clinic to "the patient in front of you" and, accordingly, the role that guidelines should play in clinical decision making by both physician and patient.

Fundamentally, the issue at hand is whether the probability of a good (or bad) outcome is greater with or without an intervention - be it surgical or medical — or with one intervention or another. Clinical decision making is an exercise in probability. We apply sophisticated statistical analytics to the results of clinical studies to help us define those probabilities, but implicit in this is a paradox. As Herbert Weisberg has beautifully elucidated in his book Willful Ignorance: The Mismeasure of Uncertainty, ${ }^{4}$ statistical probabilities based on populations are informative for the population as a whole or an individual taken at random from that population, but not directly for individuals. The application of mathematical models to clinical experience requires filtering information and discarding individual details. This is what we teach our trainees as they begin their first clinical research project: what are the critical data elements that you are going to collect on the subjects? Everything else is "ignored" in the interest of constructing a manageable database.

This critical step was first taken in 1664 by a London cloth merchant named John Graunt. ${ }^{4}$ While first Pascal and Fermat, and then others, were developing and applying the mathematics of probability to games of chance, it was not until Graunt converted London rosters of births, christenings, and deaths into tabular form that the mathematics of probability could be applied to populations. This exercise of "willful ignorance" made possible new insights and facilitated more accurate municipal life annuities that had become important sources of government funding. But in so doing, Graunt gave something up as well. To gain the power of mathematics as applied to the group, he had to discard details about the individual, and therein lies the rub. Our challenge as clinicians is to take care of the individual in front of us. As a tool, guidelines, with all their faults, summarize the best we can know about the group of individuals that share some particular characteristic or findinglike a $4.8-\mathrm{cm}$ aorta associated with a bicuspid aortic valve; however, of necessity, those guidelines cannot account for the complete constellation of characteristics that make the individual in your office uniquely "them." Are they hypertensive? Do they smoke? To be sure, we are beginning to appreciate that the fate of an aorta associated with a functionally regurgitant valve may be different than a stenotic one, but it is simply not possible to account for all aspects of each individual in a guideline. Nor should we expect 
that. Clearly, we could never account for the patient's own personal values and preferences. What guidelines represent, therefore, are a foundation to which a skilled clinician can add the details and nuance that represent the best in "clinical judgment," and not a substitute for the same.

Clinical practice guidelines are a good thing. Those who synthesize them bear a considerable burden to be thorough in their research of the data and balanced in their interpretation. We must be honest and transparent about the strengths and limitations of those data and the recommendations derived from them. At the same time, the consumer bears a responsibility to use them intelligently and with an appreciation for their inherent limitations. Accordingly, the phrase "the guidelines say" should be applied at the beginning, not the end, of the discussion.

\section{Conflict of Interest Statement}

Author has nothing to disclose with regard to commercial support.

\section{References}

1. Nishimura RA, Otto CM, Bonow RO, Carabello BA, Erwin JP III, Guyton RA, et al. 2014 AHA/ACC guideline for the management of patients with valvular heart disease: a report of the American College of Cardiology/American Heart Association Task Force on Practice Guidelines. J Thorac Cardiovasc Surg. 2014;148:e1-132.

2. Hiratzka LF, Bakris GL, Beckman JA, Bersin RM, Carr VF, Casey DE Jr, et al. 2010 ACCF/AHA/AATS/ACR/ASA/SCA/SCAI/SIR/STS/SVM guidelines for the diagnosis and management of patients with thoracic aortic disease: a report of the American College of Cardiology Foundation/American Heart Association Task Force on Practice Guidelines, American Association for Thoracic Surgery, American College of Radiology, American Stroke Association, Society of Cardiovascular Anesthesiologists, Society for Cardiovascular Angiography and Interventions, Society of Interventional Radiology, Society of Thoracic Surgeons, and Society for Vascular Medicine. Circulation. 2010;121:e266-369.

3. Hiratzka LF, Creager MA, Isselbacher EM, Svensson LG, Nishimura RA, Bonow RO, et al. Surgery for aortic dilatation in patients with bicuspid aortic valves: a statement of clarification from the American College of Cardiology/ American Heart Association Task Force on Clinical Practice Guidelines. J Am Coll Cardiol. 2010;55:1509-44.

4. Weisberg H. Willful Ignorance: The Mismeasure of Uncertainty. Hoboken, NJ Wiley; 2014

Key Words: guidelines, randomized trial, evidence-based medicine

\title{
EDITORIAL COMMENTARY
}

\section{Finding the truth in the guidelines and gospels}

\author{
Frank W. Sellke, MD
}

From the Department of Cardiothoracic Surgery, Brown Medical School and Rhode Island Hospital, Providence, RI.

Disclosures: Author has nothing to disclose with regard to commercial support.

Received for publication Feb 9, 2016; accepted for publication Feb 10, 2016; available ahead of print March 12, 2016.

Address for reprints: Frank W. Sellke, MD, Karl Karlson and Gloria Karlson Professor and Chief of Cardiothoracic Surgery, Brown Medical School and Rhode Island Hospital, 2 Dudley Street, MOC 360, Providence, RI 02905 (E-mail: fsellke@lifespan.org).

J Thorac Cardiovasc Surg 2016;151:1474-5

$0022-5223 / \$ 36.00$

Copyright (C) 2016 by The American Association for Thoracic Surgery

http://dx.doi.org/10.1016/j.jtcvs.2016.02.020

Truth is the state of being the case (www.merriam-webster. com/dictionary/truth), but a philosophical concept that depends on the knowledge, beliefs, experience, and perspective of the person wishing to be enlightened. Guidelines and the gospels are similar in that they describe concepts that to some are the absolute truth, but to others are general ideas or methods without a preconceived notion of the absolute. The American College of Cardiology (ACC)/American Heart Association (AHA) clinical guidelines are important treatises and arguably some of the most important and impactful works that these organizations create. They "guide" us in making correct clinical decisions. I had the privilege of serving as the surgical representative on the

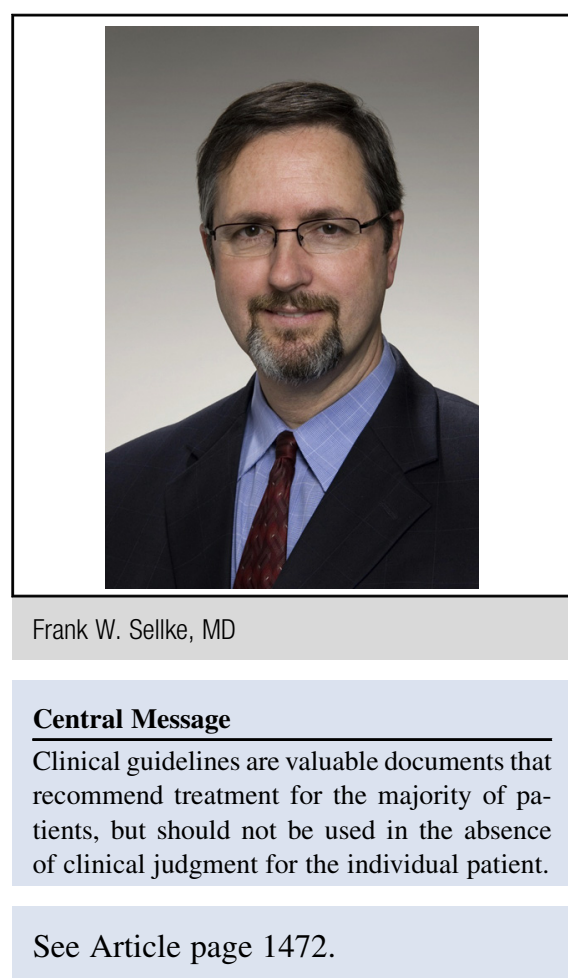

